\title{
Significance of a calcium-binding protein S100A14 expression in colon cancer progression
}

\author{
Hiroki Hashida $^{1,2} \wedge$, Robert J. Coffey ${ }^{1 \wedge}$ \\ ${ }^{1}$ Department of Medicine and Cell Biology, Vanderbilt University Medical Center, Nashville, TN, USA; ${ }^{2}$ Department of Surgical Oncology, Tazuke \\ Kofukai Medical Research Institute, Kitano Hospital, Osaka, Japan \\ Contributions: (I) Conception and design: Both authors; (II) Administrative support: Both authors; (III) Provision of study materials or patients: Both \\ authors; (IV) Collection and assembly of data: H Hashida; (V) Data analysis and interpretation: H Hashida; (VI) Manuscript writing: Both authors; \\ (VII) Final approval of manuscript: Both authors. \\ Correspondence to: Hiroki Hashida. Department of Surgery, Kobe City Medical Center General Hospital, 2-1-1 Minatojima-Minamimachi, Chuo-ku, \\ Kobe 650-0047, Japan. Email: hhashida@kcho.jp.
}

Background: The S100 proteins are characterized by two distinct EF-hand calcium-binding motifs. Several members of the S100 family are involved in cancer progression. S100A14, a member of the S100 family, has been cloned and reported in colon-specific microarray databases. In this study, we assessed the biological and functional significance of S100A14 in normal colon and in colon cancer.

Methods: The expression of S100A14 in normal colon and colon cancer was assessed. We used in situ hybridization, reverse transcription polymerase chain reaction (RT-PCR), cell migration assay, cell growth assay, western blotting, and immunohistochemical analysis. Clinicopathological examinations were also performed.

Results: $100 A 14$ is expressed in normal colon epithelium and several colon cancer cell lines. However, it is not expressed in SW480 cells. S100A14-overexpressing SW480 cells were established by stable transfection. Interestingly, a decrease in cell motility was observed, as determined using two independent migration assays. S100A14-overexpressing SW480 cells showed increased E-cadherin levels but decreased ability to form colonies in soft agar. Moreover, S100A14 expression was decreased in 95 of 154 human colon cancers, and lower S100A14 expression led to worse prognoses.

Conclusions: Our results suggest that S100A14 is involved in cell motility, adhesion, and growth changes in colon cancer and that its expression is inversely correlated with colon cancer progression. S100A14 expression in colon cancer is a useful prognostic marker.

Keywords: S100A14; calcium-binding protein; S100 family; colon cancer; cell motility

Submitted Aug 22, 2021. Accepted for publication Dec 28, 2021.

doi: 10.21037/jgo-21-528

View this article at: https://dx.doi.org/10.21037/jgo-21-528

\section{Introduction}

The S100 proteins are distinguished by two different EFhand calcium-binding motifs with different affinities. There are approximately 20 human S100 protein family members, which display unique cell- and tissue-specific expression patterns and different functions (1). In addition, genes encoding more than 15 of these $\mathrm{S} 100$ proteins are located in a cluster on human chromosome 1q21 (2). Several S100 proteins are involved in cellular activities, such as cell differentiation, cell cycle progression, signal

^ ORCID: Hiroki Hashida, 0000-0001-8044-9366; Robert J. Coffey, 0000-0002-2180-3844. 
Table 1 Relation of S100A14 expression and various prognostic factors in 154 patients with colon cancer

\begin{tabular}{|c|c|c|c|c|}
\hline S100A14 & Total no. & Positive & Negative & $P$ value \\
\hline Age (years) & & & & 0.808 \\
\hline$\leq 60$ & 79 & 31 & 48 & \\
\hline$>60$ & 75 & 28 & 47 & \\
\hline Gender & & & & 0.372 \\
\hline Female & 67 & 23 & 44 & \\
\hline Male & 87 & 36 & 51 & \\
\hline Tumour status & & & & 0.456 \\
\hline $\mathrm{T} 1$ & 19 & 9 & 10 & \\
\hline T2 & 33 & 14 & 19 & \\
\hline T3 & 74 & 25 & 49 & \\
\hline $\mathrm{T} 4$ & 28 & 10 & 18 & \\
\hline Nodal status & & & & 0.032 \\
\hline No & 75 & 36 & 39 & \\
\hline $\mathrm{N} 1$ & 37 & 13 & 24 & \\
\hline N2 & 42 & 10 & 32 & \\
\hline Pathological stage & & & & 0.052 \\
\hline I & 36 & 18 & 18 & \\
\hline II & 39 & 18 & 21 & \\
\hline III & 79 & 23 & 56 & \\
\hline Differentiation & & & & 0.890 \\
\hline Well & 36 & 15 & 21 & \\
\hline Moderately & 105 & 39 & 66 & \\
\hline Poorly & 13 & 5 & 8 & \\
\hline Total & 154 & 59 & 95 & \\
\hline
\end{tabular}

transduction, transcription, and cell migration (1), and have garnered attention owing to their involvement in several human diseases such as acute inflammatory lesions, cardiomyopathy, Alzheimer's disease, rheumatoid arthritis, and cancer $(3,4)$.

S100A4 has been shown to be upregulated in several malignant tumors (5), and it is involved in cell migration $(6,7)$. The overexpression of S100A4 leads to poor prognoses of colon and breast cancers $(8,9)$. In addition, S100A6 is related to several kinds of malignant neoplasm $(10,11)$. In contrast, $S 100 A 2$ has been described as a potential tumor suppressor gene that is downregulated in several kinds of tumor (12), and S100A2 reduces the migration of cancer cells (13).

S100A14, located on human chromosome 1q21 and consists of 4 exons and 3 introns, spanning 2,165 bp, has been cloned by analyzing a human lung cancer cell line (14). The complementary DNA (cDNA) of the open reading frame is 315 -bp long and is predicted to encode 104 amino acids. The S100A14 sequence contains two $\mathrm{Ca}^{+}$-binding EF-hand motifs, a myristoylation motif, a glycosylation site, and potential protein kinase phosphorylation sites (14).

A gene expression database for the gastrointestinal tract was created using a microarray technique (15), and using this archived database, it was found that S100A14 is more highly expressed in the colon than in the other parts of the gastrointestinal tract. Moreover, using suppression subtractive hybridization, S100A14 was found to be expressed in normal bronchial epithelium and suppressed in lung carcinoma cell lines (16). Recently, accumulating evidence has indicated that S100A14 dysregulation is correlated with tumor progression in various types of cancer (17-22). S100A14 is expressed with an epithelial phenotype; we selected this gene since it is highly expressed in the colon. Analyses of colon-specific genes may provide new insights regarding therapeutic perspectives. In this study, we assessed the biological and functional significance of S100A14 in normal colon and in colon cancer. We present the following article in accordance with the ARRIVE reporting checklist (available at https://jgo.amegroups.com/ article/view/10.21037/jgo-21-528/rc).

\section{Methods}

\section{Clinical characteristics of the patients}

The study involved 154 patients with stage I-III colorectal cancer who underwent curative surgical resection in Kitano Hospital (Osaka, Japan). The postsurgical staging of each tumor was classified according to the tumor-node-metastasis (TNM) staging system. The clinical characteristics of the patients are presented in Table 1. Eighty-seven of the patients were men and 67 were women. The median age of the patients was 61.2 (range, 29-90) years. There were 36 patients with pathological stage I, 39 with stage II, and 79 with stage III disease. The mean follow-up period was 46.5 (range, 12-60) months. The present study was approved by the Ethics Committee of the Kitano Hospital (No. 2005-11). All procedures performed in studies involving human participants were in accordance with the 
ethical standards of the institutional research committee and the Declaration of Helsinki (as revised in 2013). We obtained consent for publication from the patients.

\section{Tissue samples}

Tissue samples were obtained from patients with colon cancer who underwent colon resection in Kitano Hospital. The tumor tissues and adjacent normal tissues were kept in liquid nitrogen after surgical resection and stored at $-80{ }^{\circ} \mathrm{C}$ until use.

\section{Cell lines}

DKO-1, HCT-8, SW480, SW620, HCT116, HT-29 (colorectal cancer cell line), HCT-15, DLD-1, Caco-2, and HCA-7 cells were obtained from the American Type Culture Collection (Manassas, VA, USA) (23). All cell lines were authenticated by short tandem repeat (STR) profiling and all experiments were performed with mycoplasmafree cells. The cells were cultured in an appropriate culture medium in an incubator with a humidified atmosphere containing $95 \%$ air and $5 \% \mathrm{CO}_{2}$.

\section{Mouse samples}

A total of 2 Balb/c mice (1 male and 1 female), weighing $20 \mathrm{~g}$ and aged 5 weeks, were used. Various organs, including the brain, thymus, lung, heart, kidney, placenta, testis, spleen, liver, pancreas, esophagus, stomach, duodenum, jejunum, ileum, cecum, and colon, were collected from the mice. Mice were housed ( $\mathrm{n}=5$ per cage) with $12 \mathrm{~h}$ light/dark cycle. $\mathrm{CO}_{2}$ gas was used for mice euthanasia. All animal experiments were approved by the Institutional Animal Care and Use Committee (IACUC), in compliance with the Kitano Hospital institutional guidelines for the care and use of animals. A protocol was prepared before the study without registration.

\section{In situ bybridization}

In situ hybridization was performed following the manufacturer's instructions (Roche, Indianapolis, IN, USA). The mouse colons were harvested, fixed in $4 \%$ paraformaldehyde, embedded in optimal cutting temperature (OCT) compound, and cut into $10 \mu \mathrm{m}$ sections. The sections were placed in methanol for $2 \mathrm{~h}$ at $-20{ }^{\circ} \mathrm{C}$, acetylated in acetic anhydride/0.1 M triethanolamine
( $\mathrm{pH} 8.0$ ), equilibrated for $10 \mathrm{~min}$ in $5 \times \mathrm{SSC}[3 \mathrm{M}$ sodium chloride and $0.3 \mathrm{M}$ sodium citrate $(\mathrm{pH} 7.0)$ ], and prehybridized for $2 \mathrm{~h}$ at $60{ }^{\circ} \mathrm{C}$ in mRNA hybridization buffer (50\% formamide, $5 \times \mathrm{SSC}, 0.5 \mathrm{mg} / \mathrm{mL}$ salmon sperm DNA, $0.25 \mathrm{mg} / \mathrm{mL}$ yeast RNA, and $1 \times$ Denhardt's reagent). The sections were then hybridized with digoxigenin riboprobes $(200 \mathrm{ng} / \mathrm{mL})$ in mRNA hybridization buffer overnight at $60{ }^{\circ} \mathrm{C}$. After removing the unbound riboprobes by washing, the sections were blocked with $2 \%$ blocking reagent (Roche). Antidigoxigenin antibody (Roche) was used to detect the riboprobes according to the manufacturer's instructions. Final detection was accomplished using BM purple AP substrate (Roche/Merck, Darmstadt, Germany), and the sections were counterstained with nuclear fast red. As the negative control, sense riboprobes were used to detect any nonspecific sequences.

\section{Reverse transcription polymerase chain reaction (RT-PCR) analysis}

The total RNA was isolated from the cell lines, and the frozen normal and cancer tissues, using TRIzol reagent (Invitrogen, San Diego, CA, USA), according to the manufacturer's protocol. First-strand cDNA was synthesized with $5 \mathrm{mg}$ of total RNA using the SuperScript II RT cDNA synthesis kit (Invitrogen), following the manufacturer's protocol. For PCR amplification, $1 \mathrm{~mL}$ of reaction mixture was prepared. We titrated the amount of starting cDNA and determined the number of amplification cycles necessary to obtain reproducible quantitative performance in RT-PCR assays for mouse and human S100A14. The generated cDNAs were amplified using primers for mouse S100A14 (5'-AAACACTGACCCCTGCTGAG-3' and 5'-ACTCTTGGCTGCTTCTCCAA-3') and human S100A14 (5 '-CTGACCCCTTCTGAGCTACG-3 ' and 5'-GCCTCTCCAGCTTCACACTC-3'), using mouse glyceraldehyde-3-phosphate dehydrogenase (GAPDH) (5'-CTTCACCACCATGGAGAAGGC-3' and 5'-GGCATGGACTGTGGTCATGAG-3') and human GAPDH (5'-GACAACAGCCTCAAGATCATCA-3' and 5'-GGTCCACCACTGACACGTTG-3') as the internal controls. All subsequent assays were performed under conditions used to amplify S100A14 and GAPDH within a linear range. Twenty-eight cycles of mouse and human S100A14 PCR amplification were performed as follows: denaturation at $94{ }^{\circ} \mathrm{C}$ for $30 \mathrm{~s}$, annealing at $60{ }^{\circ} \mathrm{C}$ for $30 \mathrm{~s}$, and extension at $72{ }^{\circ} \mathrm{C}$ for $90 \mathrm{~s}$. Twenty-four cycles of mouse and human GAPDH PCR amplification were performed as 
follows: denaturation at $94^{\circ} \mathrm{C}$ for $40 \mathrm{~s}$, annealing at $60{ }^{\circ} \mathrm{C}$ for $40 \mathrm{~s}$, and extension at $72{ }^{\circ} \mathrm{C}$ for $90 \mathrm{~s}$. Ten-milliliter aliquots of the PCR products were electrophoresed on $1.5 \%$ agarose gel and visualized by ethidium bromide staining under a ultraviolet (UV) transilluminator. The negative control, S100A14 without reverse transcriptase, was not amplified. The densitometric value for $S 100 A 14$ in a given tumor or normal tissue sample was normalized by dividing by the corresponding GAPDH value. The expression ratio of the tumor was divided by that of the corresponding normal sample.

\section{S100A14 construct and stable transfectants}

According to the nucleotide sequence of human S100A14 cDNA, specific PCR primers were designed to recognize the full coding region: forward 5'-HindIIIATGGGACAGTGTCGGTCAG-3' primer 1, reverse 5'-NotI-TCAGTGCCCCCGGACAGGCC-3' primer 2. To clone the full-length cDNA encoding human $S 100 A 14$ into the expression vector pcDNA3.1 (Invitrogen), the entire coding region of $S 100 A 14$ cDNA was amplified from the total RNA derived from normal colon mucosa by RT-PCR, using primers 1 and 2, as described above. The resulting 315-bp PCR product was designed with HindIII and NotI and subcloned between the HindIII and NotI sites of pcDNA3.1. The construct was confirmed by sequencing. S100A14-pcDNA3.1 and empty pcDNA3.1 were transfected into separate SW480 cells. The transfections were initiated following the FuGENE 6 (Roche Diagnostics Corporation, IN, USA) technique. Two micrograms of plasmid were mixed with $6 \mathrm{~mL}$ of FuGENE 6 reagent and incubated in a six-well tissue culture plate containing $70 \%$ confluent cells for $24 \mathrm{~h}$ at $37{ }^{\circ} \mathrm{C}$ in a $\mathrm{CO}_{2}$ incubator. After incubation, the cells were detached using trypsin-ethylene diamine tetraacetic acid solution and passaged, at a ratio of $1: 10$, into selective medium containing $800 \mu \mathrm{g} / \mathrm{mL}$ G418 (Invitrogen). The surviving clones were identified and characterized by RT-PCR using their S100A14 mRNA expression.

\section{Cell motility}

The motility of transfected cell clones was evaluated in 24well Transwell chambers of pore size $8 \mu \mathrm{m}$ (Coster, Corning Incorporated, NY, USA). In the motility assay, $1 \times 10^{5}$ cells/ well were seeded on the filters in an appropriate culture medium and incubated for $24 \mathrm{~h}$. The cells on the upper surface were then removed by wiping with cotton swabs. The cells that had migrated through the membrane to the lower surface were fixed with ethanol and stained with Giemsa's staining solution. To quantify cells on the lower surface, cells were counted in four fields under a microscope (magnification of $\times 200$ ).

\section{Wound bealing assay}

Transfectants $\left(1 \times 10^{5}\right)$ were seeded in $0.5 \mathrm{~mL}$ of culture medium with G418 in a 24-well culture plate. After 36 h, a wound was made in the confluent monolayer with a pipette tip. The medium and debris were aspirated and replaced with $0.5 \mathrm{~mL}$ of new medium. Photographs of the wound area were captured, and again after $24 \mathrm{~h}$ of incubation. Migration was calculated as follows: filling rate $(\%)=(\mathrm{A}-\mathrm{B}) / \mathrm{A} \times 100$; where, $\mathrm{A}$ is the initial width of the wound area and $\mathrm{B}$ is the width of the wound area after 24 h. Each sample was tested in triplicate.

\section{Soft agar growth assay}

Cells $\left(1 \times 10^{5}\right)$ of each cell line were suspended in $3 \mathrm{~mL}$ of Dulbecco's modified Eagle's medium with $10 \%$ fetal calf serum and warmed to $37{ }^{\circ} \mathrm{C}$, before mixing with $300 \mathrm{~mL}$ of prewarmed $\left(52{ }^{\circ} \mathrm{C}\right) 3 \%$ agarose/phosphate-buffered saline solution. Each cell suspension was then layered into three wells (pre-coated with $1 \mathrm{~mL}$ of Dulbecco's modified Eagle's medium containing $0.6 \%$ agarose) of a six-well plate (1 mL/well). The number of colonies in each well was counted under a microscope after the cells had been cultured for 10 days.

\section{Western blotting}

Cells were lysed at $4{ }^{\circ} \mathrm{C}$ for $30 \mathrm{~min}$ in buffer containing $50 \mathrm{mM}$ Tris-HCl, (pH 7.6), $150 \mathrm{mM} \mathrm{NaCl,} 2 \mathrm{mM}$ phenylmethylsulfonyl fluoride, $0.5 \% \mathrm{NP}-40$, and $1 \%$ protease inhibitor cocktail (Sigma). Samples containing equal protein concentrations were mixed with an equivalent volume of the sample buffer [50 $\mathrm{mM}$ Tris- $\mathrm{HCl}(\mathrm{pH} 6.8)$, $10 \%$ glycerol, $2 \%$ sodium dodecyl sulfate (SDS), $0.5 \%$ 2 -mercaptoethanol, and $0.5 \%$ bromophenol blue] and boiled for $5 \mathrm{~min}$. Next, they were electrophoresed on a $10 \%$ SDS-polyacrylamide gel and transferred on to Immobilon-P membranes (Millipore, MA, USA). After washing, the nonspecific binding sites of the membrane were blocked in poly(butylene succinate) (PBS) containing $50 \mathrm{mg} / \mathrm{mL}$ nonfat 


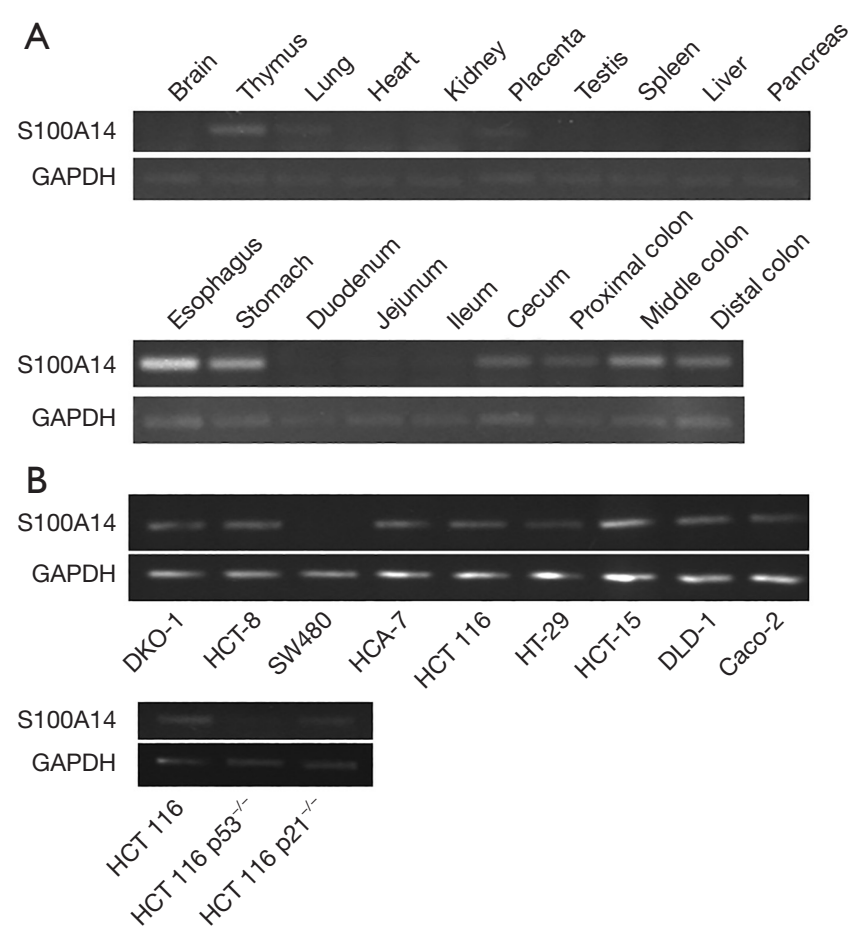

Figure 1 S100A14 expression in mouse tissues and human colon cancer cell lines. (A) Expression of S100A14 in mouse normal tissues. RT-PCR analysis showed 167 bp band following the designed primers. The same column was GAPDH as an internal control. S100A14 was expressed in thymus, lung, esophagus, stomach and colon; (B) expression of S100A14 in human colon cancer cell lines. RT-PCR analysis showed 178 bp band following the designed primers. The same column was GAPDH as an internal control. S100A14 was not expressed in SW480 cells. GAPDH, glyceraldehyde-3-phosphate dehydrogenase; RT-PCR, reverse transcription polymerase chain reaction.

skimmed milk for $1 \mathrm{~h}$. The membranes were then probed with an anti-E-cadherin monoclonal antibody $(\mathrm{mAb})(\mathrm{BD}$ Transduction Laboratories, CA, USA) diluted to 1:2,500 or anti- $\beta$-actin $\mathrm{mAb}$ (clone AC-74, Sigma, MO, USA) diluted to $1: 10,000$ for $16 \mathrm{~h}$ at $4^{\circ} \mathrm{C}$. Following $1 \mathrm{~h}$ of incubation with peroxidase-conjugated donkey anti-mouse $\operatorname{IgG}(\mathrm{H}+\mathrm{L})$ (Jackson ImmunoResearch Laboratories, PA, USA) diluted to $1: 2,500$, immunoreactive bands were visualized using Renaissance Chemiluminescent Reagent (Perkin Elmer, MA, USA).

\section{Immunohistochemical analysis}

Rabbit polyclonal antibodies against S100A14 anti-S100A14
(Proteintech, Chicago, IL, USA) were used in this study. Immunochemical staining was performed using an indirect streptavidin-biotin immunoperoxidase method [SABPO(M) kit, Nichirei Corporation, Japan]. After antigen retrieval, performed for $15 \mathrm{~min}$ in a microwave oven using $10 \mathrm{mM}$ citrate buffer, endogenous peroxidase activity was blocked with $3 \% \mathrm{H}_{2} \mathrm{O}_{2}$-methanol solution. The slides were incubated with primary antibodies (diluted 1/100) overnight at $4{ }^{\circ} \mathrm{C}$, washed with phosphate-buffered saline, and incubated with secondary biotin-labeled antibodies for $30 \mathrm{~min}$ at room temperature. Antibody localization was detected by treating the slides with peroxidaseconjugated streptavidin for $30 \mathrm{~min}$ at room temperature, followed by the diaminobenzidine reaction. The slides were counterstained with hematoxylin.

\section{Statistical analysis}

Differences between the control and experimental groups were evaluated using Analysis of Variance (ANOVA) and a post hoc test for multiple comparisons (Tukey's honestly significant difference test). The statistical significance of the differences between the incidence of S100A14 expression and clinical and pathologic parameters was assessed using the $\chi^{2}$ test. A receiver operating characteristics curve was designed to determine specificity and sensitivity. The disease-free survival rate was calculated using the KaplanMeier method. Statistical significance was examined using the log-rank test. The prognostic significance of clinicopathological factors was evaluated using univariate and multivariate regression techniques (Cox's proportional hazards model). Statistical significance was considered as $\mathrm{P}<0.05$. JMP statistical software (SAS Institute Inc., Cary, NC, USA) was used for all statistical analyses.

\section{Results}

\section{S100A14 expression in normal mouse tissues and buman colon cancer cell lines}

We examined the expression of S100A14 in normal mouse tissues using RT-PCR (Figure 1A). S100A14 RNA was detected in the thymus, lungs, esophagus, stomach, and colon, but not in the small intestine. S100A14 expression was determined in 10 colon cancer cell lines (Figure $1 B$ ). S100A14 was not expressed in SW480 cells, but all the other colon cancer cell lines expressed S100A14. In addition, S100A14 expression was lower in $553^{-/-}$HCT116 


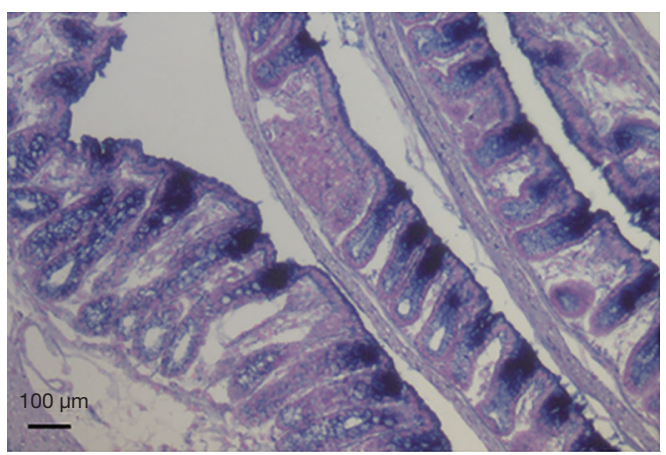

S100A14 antisense

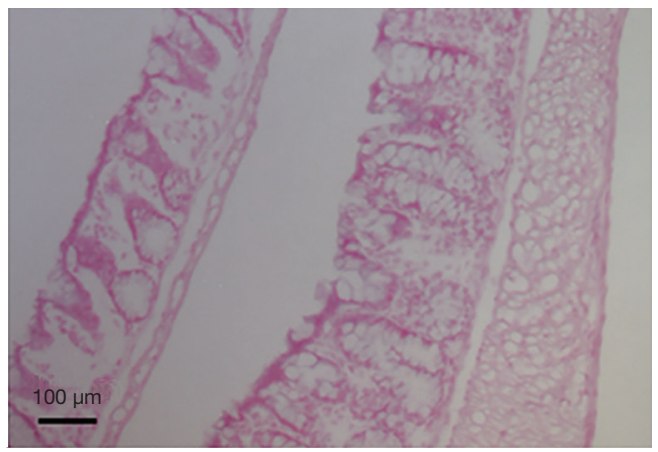

S100A14 sense

Figure 2 Expression of S100A14 in mouse normal colon. The S100A14 RNA was showed using antisense probe, and the negative control staining was showed using sense probe in in situ hybridization (BM purple staining).

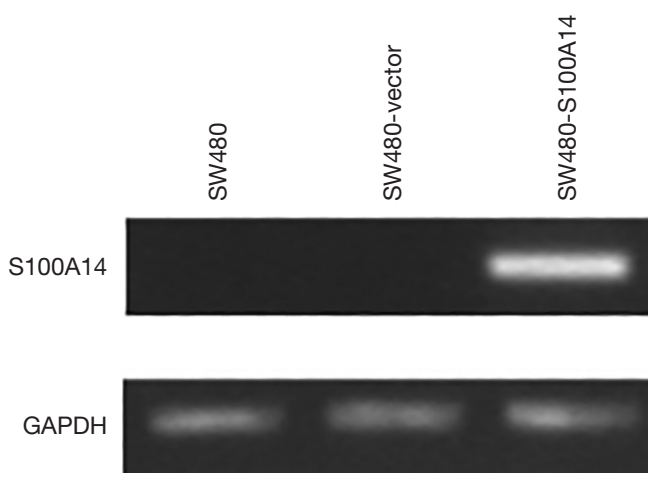

Figure 3 Expression of $S 100 A 14$ in transfectant clones was analyzed by RT-PCR, showing 315 bp band. S100A14 RNA level in transfectants were higher than both parental SW480 cell and the vector-transfected cells. RT-PCR, reverse transcription polymerase chain reaction.

cells than in parental HCT116 cells.

The results of in situ hybridization showed that S100A14 was distributed in the epithelial cells of normal mouse colon (Figure 2) and strongly expressed at the top of the crypt.

\section{Preparation of S100A14 stable transfectants}

To analyze the role of $S 100 A 14$ in colon cancer cells, stable transfectants were established. SW480 cells with the lowest $S 100 A 14$ expression were transfected with $S 100 A 14$ cDNA. Some cells were transfected with the empty vector, pcDNA3.1, as a control. The expression of $S 100 A 14$, showing a 315-bp band, in the transfectants was analyzed by RT-PCR. As shown in Figure 3, the mRNA expression of $S 100 A 14$ in the cells transfected with $S 100 A 14$ was higher than that in parental SW480 cells and vector-transfected cells.

\section{Effect of S100A14 on cell motility}

Although several members of the S100 family have been reported to have effects on cell motility, the effect of S100A14 overexpression on cell motility has not been established. To establish this effect, we first analyzed the number of S100A14 transfectant cells that had penetrated an $8 \mu \mathrm{m}$ pore filter after $24 \mathrm{~h}$ of incubation. This number was significantly lower than that for the parental and vectortransfected cells $(\mathrm{P}<0.001$, Figure 4$)$. Next, cell motility was assessed using the scratch wound assay. As shown in Figure 5, there was a four-fold decrease in the wound area after $24 \mathrm{~h}$ of incubation in the case of S100A14 transfectants $(\mathrm{P}<0.001)$. These findings show that the overexpression of S100A14 reduces cell motility.

\section{Colony formation of SW480 cells in soft agar}

The interactions between extracellular substrates and the cytoskeleton play a crucial role in cell proliferation. To examine this effect of S100A14, the transfected cells were grown in soft agar. As shown in Figure 6, the colony numbers of the S100A14 transfectants were three-fold lower than those of the parental and vector-transfected SW480 cells.

\section{Effect of S100A14 on E-cadberin expression in SW480 cells}

To examine the effect of S100A14 on E-cadherin expression, western blotting using an anti-E-cadherin $\mathrm{mAb}$ 
Cells on lower surface of micropore membrane

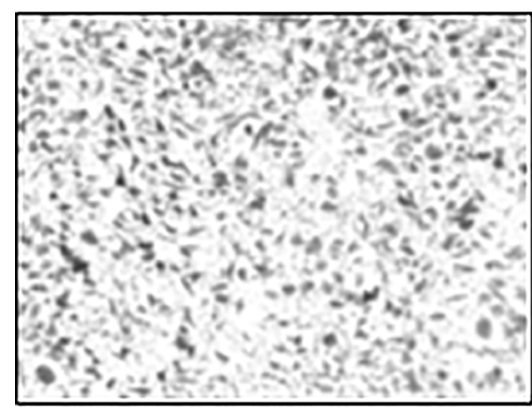

SW480

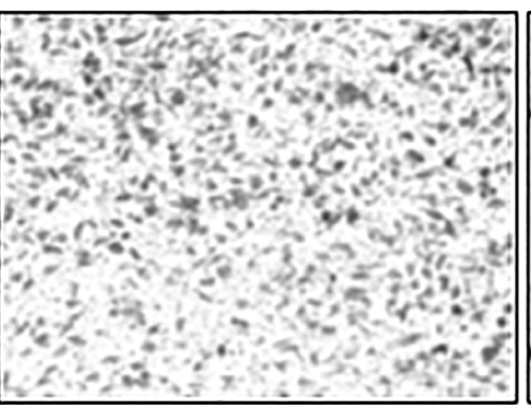

SW480-vector

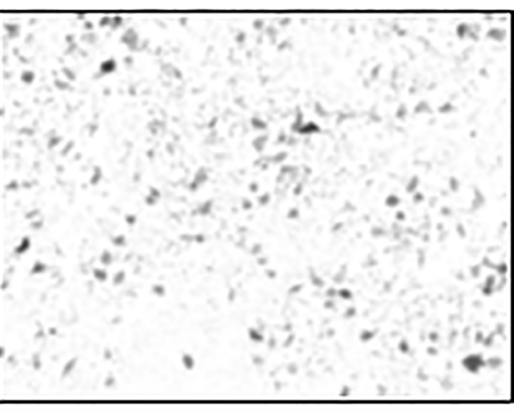

SW480-S100A14

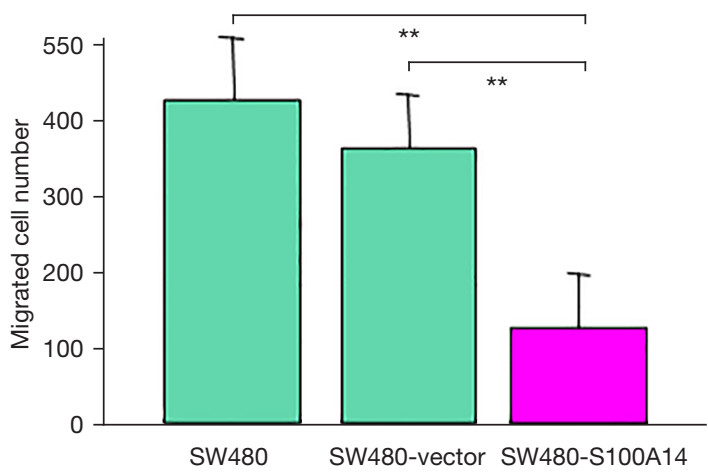

Figure 4 Effect of S100A14 on migration of SW480 cells. The number of migrated cells through the $8 \mu \mathrm{L}$ pore filter was counted. To quantify cells that had migrated to the lower surface, cells were counted in four fields, under a microscope, at a magnification of $\times 200$. Each sample was tested in triplicate and data represent the mean plus or minus the standard error. Cell migration was inhibited significantly by S100A14 over expression. **, $\mathrm{P}<0.01$.

was performed. As shown in Figure 7, E-cadherin expression in the S100A14 transfectants was lower than that in the parental SW480 and vector-transfected cells. S100A14 overexpression increased E-cadherin expression.

\section{S100A14 expression in buman colon tumor tissues}

S100A14 expression was immunohistochemically screened. We performed immunochemical staining for S100A14 expression in tissue samples from 154 patients who underwent curative resection for colon cancer. The S100A14 proteins were found to be expressed mainly on the membranes of colon cancer cells, whereas no or faint staining was observed in cancer cells of the samples (Figure 8). In colon cancer, although there are various staining patterns, the high parts of the well-differentiated areas show stronger expression.

Immunoreactivity was evaluated using a semiquantitative scoring method that was based on the proportion of positively stained tumor cells and intensity of staining. Tumor samples that showed staining of the entire membrane, as strong as that of the positive control, were assigned an intensity score of 2; tumor samples with weaker staining than the control were assigned an intensity score of 1 ; and tumor samples with negative staining were assigned an intensity score of 0 . The expression level of S100A14 in the tumor samples was scored by multiplying the percentage of positively stained cells by the intensity score. Of the 154 colon cancers studied, $68(44.2 \%)$ were classified as S100A14 positive. Immunostaining was intense and uniform on the cell membranes and $86(55.8 \%)$ were determined as S100A14 negative. 

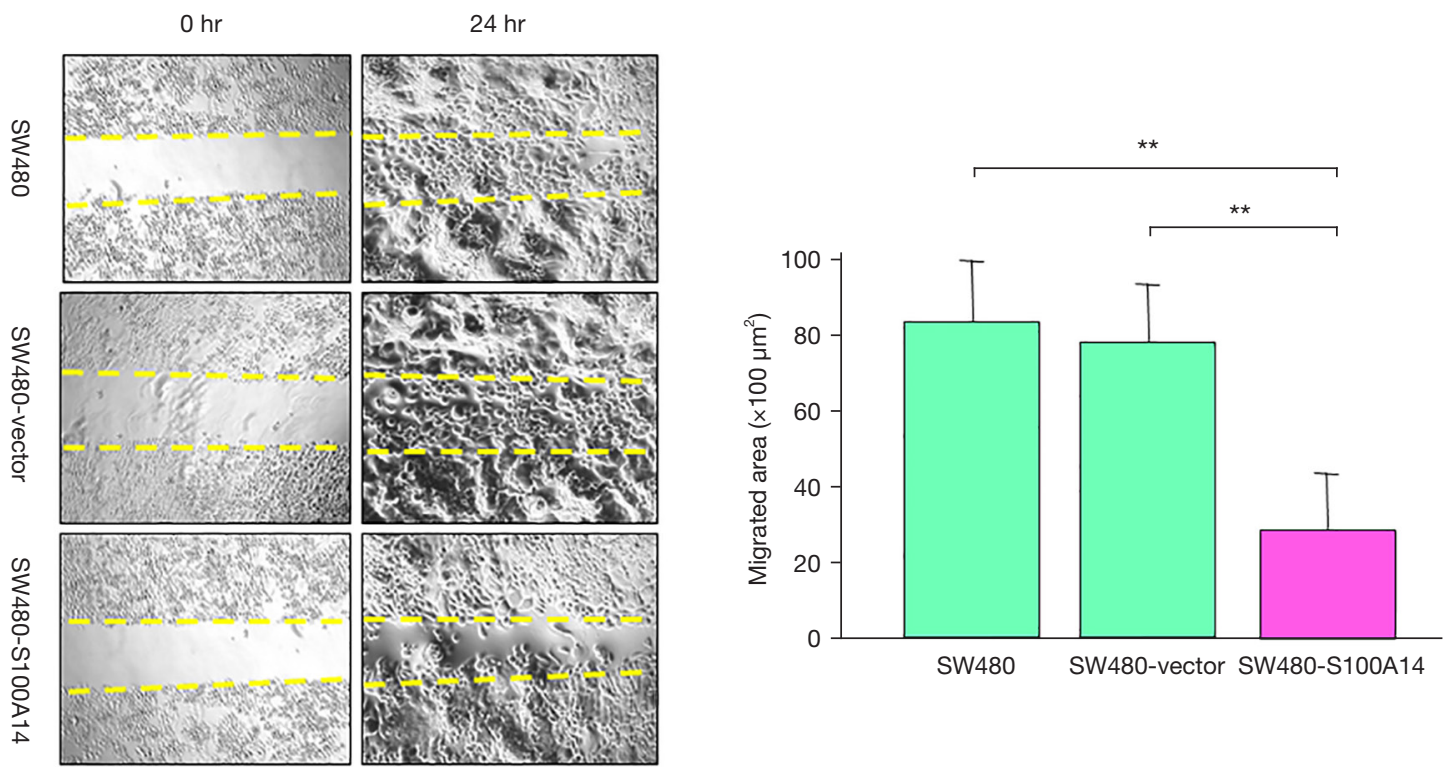

Figure 5 Scratch wound closure assay was conducted by measuring the filling rate of the wounded area. Each sample was tested in triplicate and data represent the mean plus or minus the standard error. Cell migration was inhibited significantly by S100A14 overexpression. **, $\mathrm{P}<0.01$.

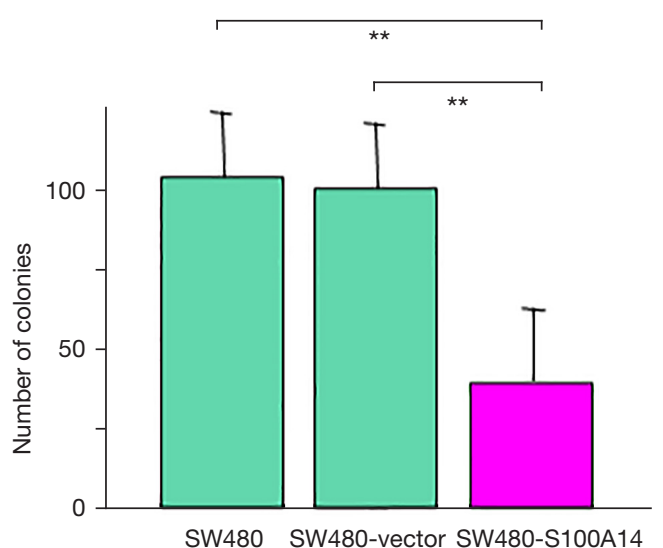

Figure 6 Effect of S100A14 in anchorage-independent growth of SW480 cells. The number of colonies in each well was counted. Colony number of the S100A14 transfectants was lower than those of parental and vector-transfected SW480 cells. ${ }^{* *}, \mathrm{P}<0.05$.

\section{S100A14 gene expression in buman colon cancer tissues}

A receiver operating characteristics curve was plotted to determine the cut-off value for S100A14 scores. S100A14 showed a significant area under the curve (AUC) of 0.835 $(\mathrm{P}<0.001)$, and 0.651 was selected as the cut-off score (Figure 9). The relative expression rates (tumor/normal

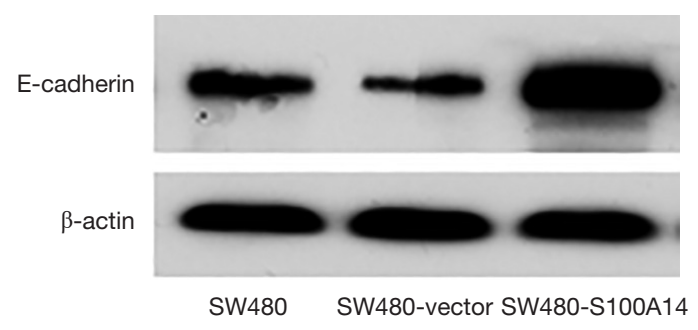

Figure 7 Effect of S100A14 in E-cadherin expression in SW480 cells. Western blot analysis was done using anti-E-cadherin $\mathrm{mAb}$ and anti- $\beta$-actin mAb. E-cadherin expression in S100A14 transfectant was lower than that in parental SW480 and vectortransfected cells. mAb, monoclonal antibody.

ratio) for $S 100 A 14$ ranged from 0 to 1.2 . The mean relative expression rate was 0.422 . Of the 154 colon cancer samples, 95 showed decreased S100A14 expression (Figure 10). The immunohistochemistry results agreed well with the RTPCR results, with the same results for $95.5 \%$ of the samples.

\section{Correlation between S100A14 expression and clinicopathological factors in colon cancer}

We assessed the correlation between the expression of S100A14 and clinicopathological factors (Table 1). Lower 

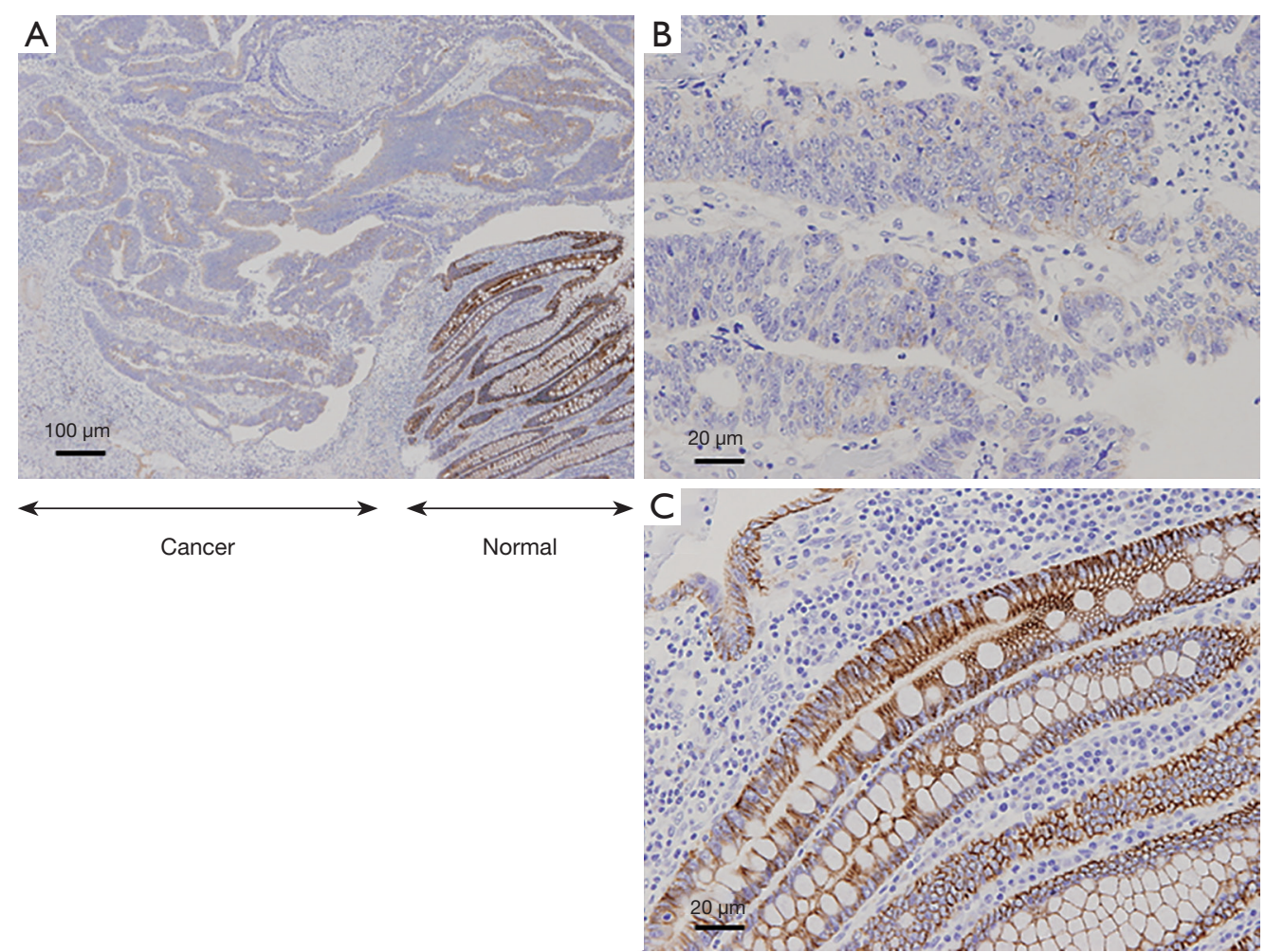

Figure 8 S100A14 expression in human colon tumor tissues. Immunostaining was performed using an indirect streptavidin-biotin immunoperoxidase method (diaminobenzidine staining). S100A14 proteins were found to be expressed mainly on the membranes of colon cancer cells. (A) $\times 40$ magnification; $(B, C) \times 200$ magnification.

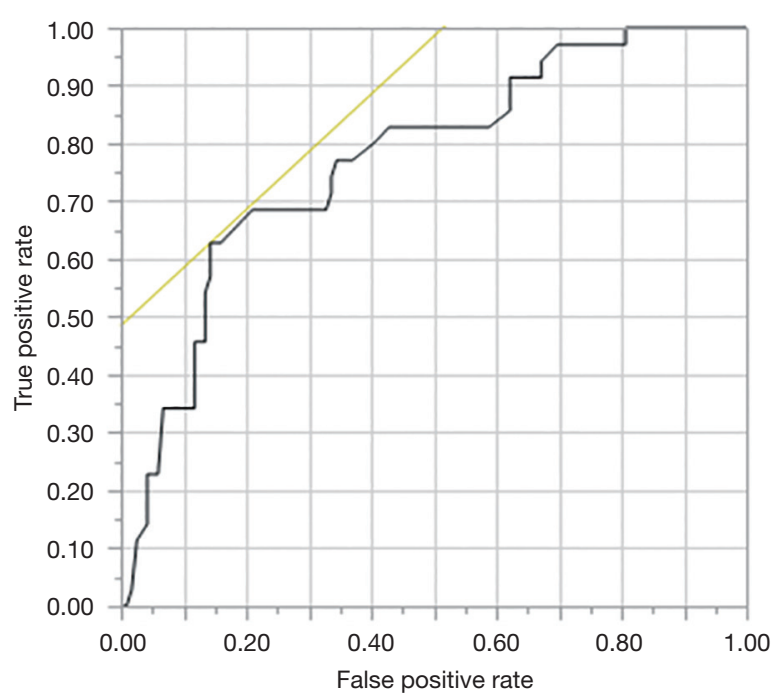

Figure 9 A receiver operating characteristics curve was plotted and analyzed to determine the optimal cut-off value for $S 100 A 14$ scores.
S100A14 expression was significantly associated with nodal status $(\mathrm{P}=0.032)$.

\section{Expression of S100A14 predicts the prognosis of colon cancer}

To analyze the correlation between S100A14 expression and the prognosis of colon cancer, Kaplan-Meier survival curves were generated. Low S100A14 expression correlated with poor outcomes ( $\mathrm{P}=0.029$, Figure 11). In the multivariate analysis, $\mathrm{S} 100 \mathrm{~A} 14$ expression $(\mathrm{P}=0.004)$ had a significant prognostic value for overall survival (Table 2).

\section{Discussion}

The S100 protein family is involved in various intracellular and extracellular activities, such as the modulation of cell differentiation and proliferation, cell-cell communication, intracellular signaling, cell motility, and cell structure. 

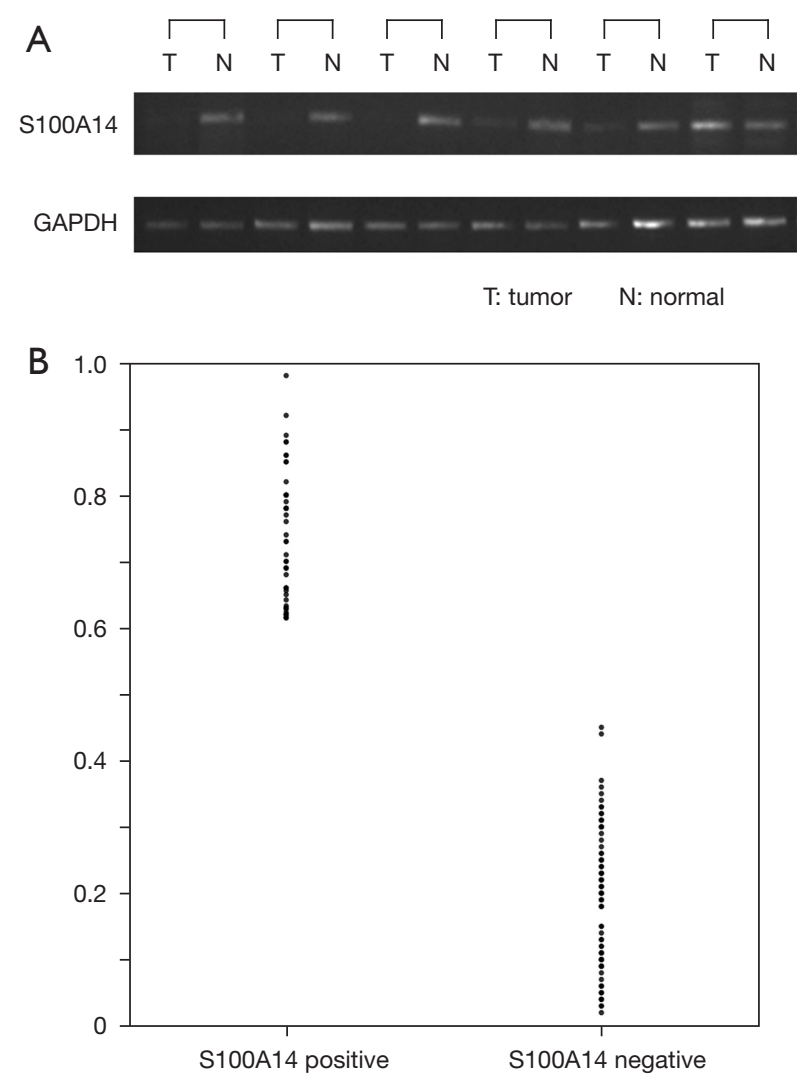

Figure 10 S100A14 expression values in human colon tissues. (A) S100A14 expression in human colon tumor tissues and normal colon tissues. The values were obtained from the expression ratio of a given tumor sample divided by that of the corresponding normal sample; (B) the scatter plot of relative expression ration of S100A14. GAPDH, glyceraldehyde-3-phosphate dehydrogenase.

The members of this family show cell- and tissue-specific expression (1), and some members are secreted from cells exerting extracellular, cytokine-like activities, through the surface receptor for glycation end-products, and have paracrine effects (2).

The malignancy-promoting effects of several S100 members have been proposed. The altered expression of $S 100$ in malignant tumors plays important roles as a prognostic and diagnostic factor (9). In addition, the S100A4 protein acts as an angiogenic factor (24), and S100P has been identified as a hypomethylation target in pancreatic cancer (25). In contrast, $S 100 A 2$ has been described as a potential tumor suppressor gene and is downregulated in several tumors (26). Briefly, S100A2 is inversely correlated with tumor progression. Moreover, the S100 proteins are regulated by various kinds of molecules. For example, erbB2

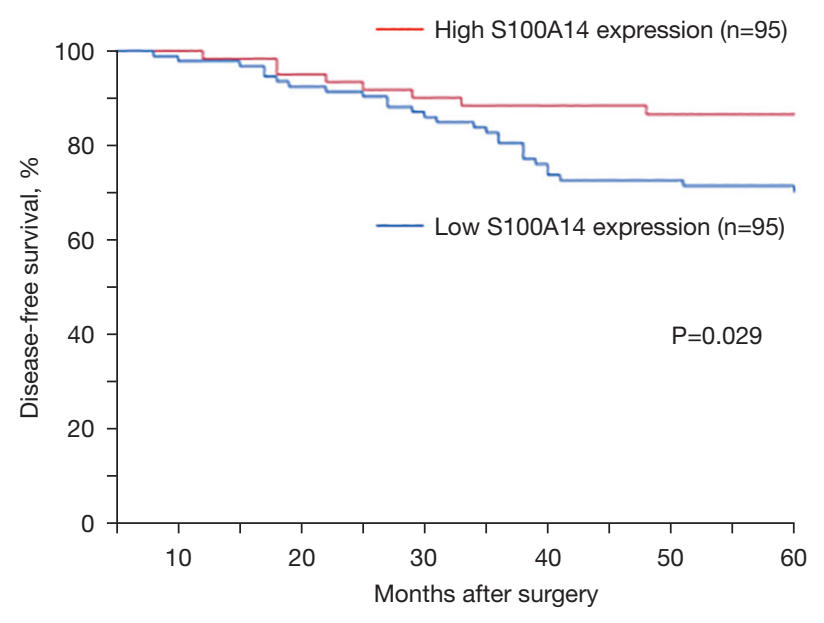

Figure 11 Expression of $S 100 A 14$ predicts the prognosis of colon cancer patients. Low $S 100 A 14$ expression was correlated with poor outcomes $(\mathrm{P}=0.029)$. Red line: high S100A14 expression. Blue line: low $S 100 A 14$ expression.

upregulates S100A4 expression in medulloblastomas (27) and S100A4 regulates the membrane-induced activation of matrix metalloproteinase-2 in osteosarcoma cells (28).

$\mathrm{S} 100 \mathrm{~A} 14$, a new member of the $\mathrm{S} 100$ protein family, is differentially regulated in tumors. S100A14 is encoded in several epithelial tissues, and it is highly expressed in the colon. Different S100A14 expression patterns have been reported in different tumors. Genomic instability of the human chromosomal region $1 \mathrm{q} 21$ is often observed and is involved in various tumors. S100A14 is closely related to $S 100 A 16 / S 100 A 13 / S 100 A 1$, which has previously been physically mapped to the $1 \mathrm{q} 21$ chromosomal region (14).

Many molecular markers of colon cancer have been examined to date, and an enhanced understanding of the genetic events that occur during neoplastic progression in the colon could lead to improvements in survival. Therefore, analyses of colon-specific genes may be useful for new therapeutic perspectives. Our data show that S100A14 is highly expressed in the epithelial cells of the mouse colon. S100A14 was expected to be expressed in the colon based on a microarray database of the gastrointestinal tract (15). We found that the potentially tissue-specific expression of S100A14 might be important for regulating cell proliferation and differentiation. In addition, we found that S100A14 was downregulated in human colon tumors. Moreover, using the suppression subtractive hybridization technique, it was previously found that $S 100 A 14$ is also downregulated in lung cancer cell lines (16). These data 
Table 2 Multivariate regression analysis in predicting the diseasefree and overall survival of 154 patients

\begin{tabular}{|c|c|c|c|}
\hline Variable & Assigned score & Hazard ratio (95\% Cl) & $P$ value \\
\hline S100A14 & & & 0.004 \\
\hline Positive & 0 & $0.309(0.114-0.708)$ & \\
\hline Negative & 1 & & \\
\hline Tumor status & & & 0.841 \\
\hline T1 & 1 & $0.862(0.171-3.440)$ & \\
\hline T2 & 2 & & \\
\hline T3 & 3 & & \\
\hline $\mathrm{T} 4$ & 4 & & \\
\hline Nodal status & & & 0.365 \\
\hline No & 0 & $0.667(0.273-1.611)$ & \\
\hline $\mathrm{N} 1$ & 1 & & \\
\hline N2 & 2 & & \\
\hline Differentiation & & & 0.127 \\
\hline Well & 0 & $0.476(0.143-1.299)$ & \\
\hline Moderately & 1 & & \\
\hline Poorly & 2 & & \\
\hline
\end{tabular}

suggest the distinct regulation and potential roles of S100A14 in malignant tumor progression.

Cell motility is an essential function in tumor progression and metastasis. Several members of the $\mathrm{S} 100$ family regulate cell motility and metastasis in various kinds of malignant cells. For example, a positive correlation was observed between the metastatic potential of murine mammary adenocarcinoma cells and the level of expression of S100A4 (29). A similar correlation has been found in B16 melanoma cells (30). S100A4 expression in mouse mammary tumour virus-neu (MMTV-neu) transgenic mice leads to the metastasis of mammary tumors (31), and the antisense RNA to S100A4 in highly metastatic Lewis lung carcinoma cells suppresses cell motility and invasiveness (32). In addition, S100A6 is related to cell migration in glioblastoma cells (33) and S100A2 reduces cell migration (13). In this study, we addressed these points using SW480 colon carcinoma cells overexpressing S100A14 and elucidated the mechanisms leading to these changes. Briefly, to test the effect of S100A14 on the invasive abilities of colon cancer cells, we performed two in vitro motility assays. They revealed an inverse correlation between the expression level of S100A14 and cell motility. This study suggests that S100A14, like other parts of the S100 family, is involved in cell motility and cancer progression.

p53 is a tumor suppressor gene and the loss of normal function of the $\mathrm{p} 53$ protein is associated with carcinogenesis. $p 21$ is the downstream target gene of $p 53$, and it is responsible for $p 53$-induced $\mathrm{G}_{1}$ arrest and inhibits the protein kinase activities of $\mathrm{G}_{1}$ cyclin/cyclin-dependent protein kinase $(\mathrm{CDK})$ complexes, thereby preventing the phosphorylation of retinoblastoma (RB). This in turn inhibits cell growth. S100A4 interacts with wild-type p53 to stimulate apoptosis, and the interaction with S100A4 may modulate the functions of p53 (34,35). Interestingly, we found that S100A14 expression was lower in $p 53^{-/-}$HCT116 cells than in parental HCT116 cells. These findings suggest that the expression of S100A14 may be regulated by $\mathrm{p} 53$. In addition, it was reported that S100A14 is involved in cell invasion by affecting the expression and function of matrix metalloproteinase (MMP)-2 via p53-dependent transcription (17).

The attachment of cancer cells to extracellular matrices and cell motility are essential steps for invasion. E-Cadherin plays an important role in this process, as it is a powerful molecule involved in epithelial cell adhesion and epithelial organization. Although $\beta$-catenin binds directly to the cytoplasmic tail of E-cadherin, $\alpha$-catenin links the bound $\beta$-catenin to the actin cytoskeleton (36). Calcium ions are known to play an important role in cell motility via the regulation of E-cadherin proteolysis (37). In the S100 family, S100A4 is involved in E-cadherin expression in gallbladder carcinomas (38) and gastric cancer (39). To analyze the mechanism underlying the decreased invasiveness of SW480 cells overexpressing S100A14, we examined the effects of E-cadherin on the adhesive abilities of SW480 cells. We found that the expression of E-cadherin in the S100A14 transfectants was higher than that in the parental and vector-transfected SW480 cells. Furthermore, growth in soft agar, which affects the loss of cell-substrate adhesion, cell growth, and survival, is often used as an indicator of enhanced metastatic ability of cancer cells. The effect of S100A14 overexpression on the anchorage independence of tumor cells is still unknown. In this study, we demonstrated that S100A14 might be involved in these functions.

The expression of S100A14 was not correlated with any prognostic parameters, such as tumor status, nodal status, pathologic stage, or tumor differentiation, of colon cancer but was correlated with disease-free survival of patients 
with colon cancer. In multivarious analysis, S100A14 was an independent prognostic factor, and its expression was inversely correlated with the prognosis of colorectal cancer. By regulating the expression of S100A14, the progression of colorectal cancer can be controlled.

This study has some limitations. The mechanism of S100A14 in promoting cell migration and invasion requires further elucidation to provide insights into colon cancer metastasis. Analysis of intracellular signal transduction may help clarify the mechanism. In addition, animal model assays are required to confirm S100A14 function in metastasis in vivo. The underlying potential mechanism between S100A14 and epithelial-mesenchymal transition warrants further investigations.

Our current data from S100A14 transfectants show the suppressive effect of S100A14 on cell adhesion, cell motility, and tumor progression. S100A14 could be viewed as a new tool to gain insights into the epithelial organization of normal colon and colon cancer cell lines. Although further detailed studies on S100A14 in different organ tumors are needed, this molecule may be a promising target for new therapeutic strategies.

\section{Conclusions}

S100A14 is highly expressed in the gastrointestinal tract, especially in the colon. Using a colorectal cancer cell line, we investigated the expression mechanism of S100A14 and analyzed its expression in actual human colorectal cancer. The expression of S100A14 is inversely related to prognosis. It means that by regulating the expression of S100A14, the progression of colorectal cancer can be controlled.

\section{Acknowledgments}

Funding: This work was supported by the Grant-inAid for Scientific Research (C) (KAKENHI) (18591491 and 20591599 to $\mathrm{HH}$ ), and Osaka Cancer Foundation and Kitano Research Award. RJC is supported by NCI R35CA197570 and the Vanderbilt-Ingram Cancer Center Special Programs of Research Excellence (SPORE) in GI Cancer P50CA236733.

\section{Footnote}

Reporting Checklist: The authors have completed the ARRIVE reporting checklist. Available at https://jgo. amegroups.com/article/view/10.21037/jgo-21-528/rc
Data Sharing Statement: Available at https://jgo.amegroups. com/article/view/10.21037/jgo-21-528/dss

Conflicts of Interest: Both authors have completed the ICMJE uniform disclosure form (available at https://jgo.amegroups. com/article/view/10.21037/jgo-21-528/coif). HH reports funding support from a Grant-in-Aid for Scientific Research (C) (KAKENHI) (18591491 and 20591599), and Osaka Cancer Foundation and Kitano Research Award. The other author has no conflicts of interest to declare.

Ethical Statement: The authors are accountable for all aspects of the work in ensuring that questions related to the accuracy or integrity of any part of the work are appropriately investigated and resolved. The present study was approved by the Ethics Committee of the Kitano Hospital (No. 2005-11). All procedures performed in studies involving human participants were in accordance with the ethical standards of the institutional research committee and the Declaration of Helsinki (as revised in 2013). We obtained consent for publication from the patients. All animal experiments were approved by the IACUC, in compliance with Kitano Hospital institutional guidelines for the care and use of animals. A protocol was prepared before the study without registration.

Open Access Statement: This is an Open Access article distributed in accordance with the Creative Commons Attribution-NonCommercial-NoDerivs 4.0 International License (CC BY-NC-ND 4.0), which permits the noncommercial replication and distribution of the article with the strict proviso that no changes or edits are made and the original work is properly cited (including links to both the formal publication through the relevant DOI and the license). See: https://creativecommons.org/licenses/by-nc-nd/4.0/.

\section{References}

1. Heizmann CW, Fritz G, Schäfer BW. S100 proteins: structure, functions and pathology. Front Biosci 2002;7:d1356-68.

2. Schäfer BW, Wicki R, Engelkamp D, et al. Isolation of a YAC clone covering a cluster of nine S100 genes on human chromosome 1q21: rationale for a new nomenclature of the S100 calcium-binding protein family. Genomics 1995;25:638-43.

3. Remppis A, Greten T, Schäfer BW, et al. Altered expression of the $\mathrm{Ca}(2+)$-binding protein $\mathrm{S} 100 \mathrm{~A} 1$ in human 
cardiomyopathy. Biochim Biophys Acta 1996;1313:253-7.

4. Masuda K, Masuda R, Neidhart M, et al. Molecular profile of synovial fibroblasts in rheumatoid arthritis depends on the stage of proliferation. Arthritis Res 2002;4:R8.

5. Gupta S, Hussain T, MacLennan GT, et al. Differential expression of S100A2 and S100A4 during progression of human prostate adenocarcinoma. J Clin Oncol 2003;21:106-12.

6. Jenkinson SR, Barraclough R, West CR, et al. S100A4 regulates cell motility and invasion in an in vitro model for breast cancer metastasis. Br J Cancer 2004;90:253-62.

7. Belot N, Pochet R, Heizmann CW, et al. Extracellular S100A4 stimulates the migration rate of astrocytic tumor cells by modifying the organization of their actin cytoskeleton. Biochim Biophys Acta 2002;1600:74-83.

8. Gongoll S, Peters G, Mengel M, et al. Prognostic significance of calcium-binding protein S100A4 in colorectal cancer. Gastroenterology 2002;123:1478-84.

9. Rudland PS, Platt-Higgins A, Renshaw C, et al. Prognostic significance of the metastasis-inducing protein S100A4 (p9Ka) in human breast cancer. Cancer Res 2000;60:1595-603.

10. Stulík J, Osterreicher J, Koupilová K, et al. Differential expression of the $\mathrm{Ca} 2+$ binding S100A6 protein in normal, preneoplastic and neoplastic colon mucosa. Eur J Cancer 2000;36:1050-9.

11. Komatsu K, Andoh A, Ishiguro S, et al. Increased expression of S100A6 (Calcyclin), a calcium-binding protein of the S100 family, in human colorectal adenocarcinomas. Clin Cancer Res 2000;6:172-7.

12. Feng G, Xu X, Youssef EM, et al. Diminished expression of S100A2, a putative tumor suppressor, at early stage of human lung carcinogenesis. Cancer Res 2001;61:7999-8004.

13. Nagy N, Brenner C, Markadieu N, et al. S100A2, a putative tumor suppressor gene, regulates in vitro squamous cell carcinoma migration. Lab Invest 2001;81:599-612.

14. Pietas A, Schlüns K, Marenholz I, et al. Molecular cloning and characterization of the human S100A14 gene encoding a novel member of the S100 family. Genomics 2002;79:513-22.

15. Bates MD, Erwin CR, Sanford LP, et al. Novel genes and functional relationships in the adult mouse gastrointestinal tract identified by microarray analysis. Gastroenterology 2002;122:1467-82.

16. Difilippantonio S, Chen Y, Pietas A, et al. Gene expression profiles in human non-small and small-cell lung cancers. Eur J Cancer 2003;39:1936-47.
17. Chen H, Yuan Y, Zhang C, et al. Involvement of S100A14 protein in cell invasion by affecting expression and function of matrix metalloproteinase (MMP)-2 via p53-dependent transcriptional regulation. J Biol Chem 2012;287:17109-19.

18. Cho H, Shin HY, Kim S, et al. The role of S100A14 in epithelial ovarian tumors. Oncotarget 2014;5:3482-96.

19. Chen H, Ma J, Sunkel B, et al. S100A14: novel modulator of terminal differentiation in esophageal cancer. Mol Cancer Res 2013;11:1542-53.

20. Qian J, Ding F, Luo A, et al. Overexpression of S100A14 in human serous ovarian carcinoma. Oncol Lett 2016;11:1113-9.

21. Tanaka M, Ichikawa-Tomikawa N, Shishito N, et al. Coexpression of S100A14 and S100A16 correlates with a poor prognosis in human breast cancer and promotes cancer cell invasion. BMC Cancer 2015;15:53.

22. Zhu M, Wang H, Cui J, et al. Calcium-binding protein S100A14 induces differentiation and suppresses metastasis in gastric cancer. Cell Death Dis 2017;8:e2938.

23. Bunz F, Hwang PM, Torrance C, et al. Disruption of $\mathrm{p} 53$ in human cancer cells alters the responses to therapeutic agents. J Clin Invest 1999;104:263-9.

24. Ambartsumian N, Klingelhöfer J, Grigorian M, et al. The metastasis-associated Mts1(S100A4) protein could act as an angiogenic factor. Oncogene 2001;20:4685-95.

25. Sato N, Fukushima N, Matsubayashi H, et al. Identification of maspin and S100P as novel hypomethylation targets in pancreatic cancer using global gene expression profiling. Oncogene 2004;23:1531-8.

26. Maelandsmo GM, Flørenes VA, Mellingsaeter T, et al. Differential expression patterns of S100A2, S100A4 and S100A6 during progression of human malignant melanoma. Int J Cancer 1997;74:464-9.

27. Hernan R, Fasheh R, Calabrese C, et al. ERBB2 upregulates $\mathrm{S} 100 \mathrm{~A} 4$ and several other prometastatic genes in medulloblastoma. Cancer Res 2003;63:140-8.

28. Mathisen B, Lindstad RI, Hansen J, et al. S100A4 regulates membrane induced activation of matrix metalloproteinase-2 in osteosarcoma cells. Clin Exp Metastasis 2003;20:701-11.

29. Ebralidze A, Tulchinsky E, Grigorian M, et al. Isolation and characterization of a gene specifically expressed in different metastatic cells and whose deduced gene product has a high degree of homology to a $\mathrm{Ca} 2+-$ binding protein family. Genes Dev 1989;3:1086-93.

30. Lakshmi MS, Parker C, Sherbet GV. Metastasis associated MTS1 and NM23 genes affect tubulin polymerisation in 
B16 melanomas: a possible mechanism of their regulation of metastatic behaviour of tumours. Anticancer Res 1993;13:299-303.

31. Davies MP, Rudland PS, Robertson L, et al. Expression of the calcium-binding protein S100A4 (p9Ka) in MMTVneu transgenic mice induces metastasis of mammary tumours. Oncogene 1996;13:1631-7.

32. Takenaga K, Nakamura Y, Sakiyama S. Expression of antisense RNA to S100A4 gene encoding an S100-related calcium-binding protein suppresses metastatic potential of high-metastatic Lewis lung carcinoma cells. Oncogene 1997;14:331-7.

33. Kucharczak J, Pannequin J, Camby I, et al. Gastrin induces over-expression of genes involved in human U373 glioblastoma cell migration. Oncogene 2001;20:7021-8.

34. Grigorian M, Andresen S, Tulchinsky E, et al. Tumor suppressor $\mathrm{p} 53$ protein is a new target for the metastasisassociated Mts1/S100A4 protein: functional consequences

Cite this article as: Hashida H, Coffey RJ. Significance of a calcium-binding protein S100A14 expression in colon cancer progression. J Gastrointest Oncol 2022;13(1):149-162. doi: 10.21037/jgo-21-528 of their interaction. J Biol Chem 2001;276:22699-708.

35. Chen H, Fernig DG, Rudland PS, et al. Binding to intracellular targets of the metastasis-inducing protein, S100A4 (p9Ka). Biochem Biophys Res Commun 2001;286:1212-7.

36. Takeichi M. Morphogenetic roles of classic cadherins. Curr Opin Cell Biol 1995;7:619-27.

37. Rios-Doria J, Day KC, Kuefer R, et al. The role of calpain in the proteolytic cleavage of E-cadherin in prostate and mammary epithelial cells. J Biol Chem 2003;278:1372-9.

38. Kohya N, Kitajima Y, Jiao W, et al. Effects of E-cadherin transfection on gene expression of a gallbladder carcinoma cell line: repression of MTS1/S100A4 gene expression. Int J Cancer 2003;104:44-53.

39. Yonemura Y, Endou Y, Kimura K, et al. Inverse expression of S100A4 and E-cadherin is associated with metastatic potential in gastric cancer. Clin Cancer Res 2000;6:4234-42. 